\title{
Failure of the Ricardian Equivalence Theory in Economies with Incomplete Markets*
}

Jose Angelo Divino** $^{* *}$

Jaime Orrillo ${ }^{* * *}$

\begin{abstract}
We investigate whether the Ricardian Equivalence Theorem (RET) holds in an economy with incomplete financial markets and lump-sum taxes. Even in this artificially favorable environment, where public debt has a perfect substitute, the RET fails if we allow for the payoff matrix to vary. For the RET to hold, we need to assume that the risk-free payoff belongs to the asset span of the economy and the law of one price is valid. Given that these are strong assumptions, we show that the failure of the RET is robust, in the sense that there exists an open set of payoff matrices such that the RET does not hold.
\end{abstract}

Keywords: Ricardian Equivalence Theorem; Incomplete financial markets; Asset span.

JEL Codes: D52, E62.

\footnotetext{
${ }^{*}$ Submitted in October 2015. Revised in March 2017. The authors would like to thank Giuseppe Moscarini, Miguel Leon-Ledesma and participants in seminars at Catholic University of Brasilia, University of Brasilia, Instituto Nacional de Matemática Pura e Aplicada (IMPA) and in the Latin American Meeting of the Econometric Society for helpful comments and suggestions. Jose A. Divino and Jaime Orrillo thank CNPq from Brazil for financial support. Any remaining errors are the authors' sole responsibility.

${ }^{* *}$ Graduate Program of Economics, Catholic University of Brasilia, Brazil.

E-mail: jangelo@pos.ucb.br

${ }^{* * *}$ Corresponding author. Graduate Program of Economics, Catholic University of Brasilia. SGAN 916, office A-125, Asa Norte, Brasilia, DF, Zip: 70.790-160, Brazil. Phone: +55(61)34487186. Fax: +55(61)3347-4797.

E-mail: orrillo@pos.ucb.br
}

Brazilian Review of Econometrics v. $37, \mathrm{n}^{\circ} 1$, pp. $19-30$ May 2017 


\section{Introduction}

The Ricardian Equivalence Theorem (RET), which states that the real sector of the economy is not affected by the way in which the government finances its spending, was firstly formulated by David Ricardo in 1820. Since then, the RET has become a polemic and controversial subject among economists who have investigated either its theoretical or empirical validity. Bernheim (1987), Seater (1993), Elmendorf and Mankiw (1999), and Ricciuti (2003), for instance, are among those who stress issues arising from required assumptions and empirical approaches applied to analyze the RET.

Under restrictive assumptions, such as perfect capital markets, Barro (1974) showed that the fiscal policy enacted by the government does not affect households' optimal consumption decisions. This result is arguable in the literature, provoking opposite responses by influential economists such as Buchanan (1976) and Feldstein (1974). ${ }^{1}$ The Barro's result has been extend to various settings where at least one of his primary assumption has been dropped. In some settings, such as in Auerbach and Kotlikoff (1987), Trostel (1993), Braun (1994) and McGrattan (1994), the RET no longer holds. In others, however, it continues to hold provided that suitable additional conditions are assumed, as in Gale (1990), Bassetto and Kocherlakota (2004), Yotsuzuka (1987), Hayashi (1987) and Hayford (1989), Panadés (2001) and Evans et al. (2012).

The goal of this paper is to investigate whether the RET holds in the presence of incomplete financial markets. Our framework is the simplest possible in the sense that taxes are lump-sum and the public debt has a perfect substitute. ${ }^{2}$ More precisely, agents in our model are affected by the riskless interest rate which is exogenously given. We can think, for instance, that the government uses an auction to sell treasury bills and determine the riskless interest rate. Then, the government enters in the economy by enacting a fiscal policy which affects all agents. Our concern is whether or not the RET holds for agents who have access to incomplete financial market, do not negotiate public bonds directly, and take as given the financial structure to transfer wealth.

Our main result states that, in general, the government debt is not neutral in this naive framework, which incorporates incomplete financial markets and lumpsum taxes. The problem lies in the fact that agents are not able to replicate the effects of the fiscal policy in the second-period budget constraint and therefore are unable to neutralize the public debt, unless the law of one price is satisfied. If this is the case, then we show that the RET holds if and only if the risk-free payoff belongs to the asset span representing the set of all marketable payoffs. The law of one price, however, has been found to be a problematic assumption. Surveys about its anomalies and failure might be found in Lamont and thaler (2003) and

\footnotetext{
${ }^{1}$ See Barro (1976) for a replay.

${ }^{2}$ See Chan (1983) for a detailed discussion on the neutrality of government financing policy in this framework.
} 
Biondo (2010), respectively. Lastly, we show that even assuming the law of one price, the conditions under which the RET holds are not robust in the sense that there exists an open set of payoff matrices such that the RET fails.

It is useful to point out some peculiarities of our model. Agents have access to an incomplete financial market spanned by risky-assets where none of them is the public debt, which is assumed to be risk-free. The reasons for the exclusion of the public debt from the set of spanning assets, which are assumed to be issued by the private sector, can be found in Holmstrom and Tirole (1998). They provide foundations for the private sector's inability to produce risk-free assets. Concerning to the methodology, we follow the framework used to show irrelevance results, such as the Modigliani-Miller Theorem (MMT) on the indeterminacy of the firm's financial policy, since the RET is ultimately nothing else than the MMT on pubic finance, as noticed by Wallace (1981).

Finally, the fiscal policy given by a tax cut will be neutralized if, and only if, the financial structure replicates the risk-free payoff. This does not mean that the risk-free asset shall replicate any tax structure. In that sense, the necessary and sufficient condition for the RET to hold stating that the risk-free payoff belongs to the asset span is not robust. That is, if we change the tax structure, the risk-free payoff might no longer replicate any public debt. This should not be understood as a failure of the RET but rather that the condition that guarantees the RET simply does not apply to this new setting where the tax structure has been modified.

The paper is organized as follows. The next Section describes the model economy, defines the risk-free payoff and the fiscal policy used by the government, and solves the taxpayer's problem. The third Section shows how the law of one price is essential to demonstrate the RET. The fourth Section explains the failure of the RET. Finally, the fifth Section is dedicated to the concluding remarks.

\section{The Model}

We consider a two-period finance economy derived from a GEI multi-good economy, which includes government. ${ }^{3}$ Following the Ricardian equivalence literature, we will consider an expansionist fiscal policy that is implemented through tax cuts and increases in government spending, as in Hayford (1989).

There is uncertainty only in the second period which is represented by a finite set $S=\{1, \ldots, S\}$ of states of nature. The economy consists of $H$ individuals, a financial structure and government. Individuals are characterized by their utility functions $U^{h}: \mathbb{R}_{+}^{S+1} \rightarrow \mathbb{R}$ and initial endowments $\omega^{h} \in \mathbb{R}_{++}^{S+1}$. The utility $U^{h}$ is assumed to be strictly increasing in order for the budget constraint to be satisfied with equality. ${ }^{4}$

The financial structure is modeled by the payoff matrix $V \in \mathbb{R}_{+}^{S \times J}$ of the $J$

\footnotetext{
${ }^{3}$ See Geanakoplos (1990) and Magill and Quinzii (2002) for a detailed discussion on this basic framework.

${ }^{4}$ We also assume that $U^{h}$ is a V.N.M. utility function with beliefs having full support.
} 
assets available for trade in the first period. Here, $\mathbb{R}_{+}^{S \times J}$ denotes the set of all matrixes with $S$ rows and $J$ columns as in Dubey et al. (2005). ${ }^{5}$ Each column $r^{j}$ of $V$ represents the state-contingent payoff of each asset $j \in J$ to be paid in the second period. Thus, the $J$ assets are assumed to be risky. That is, for each $j \in J$ there exist at least two states $s$ and $s^{\prime}$ with $r_{s}^{j} \neq r_{s^{\prime}}^{j}$.

It is useful to define the transference space for the finance economy to be the asset span, which in turn is defined by the sub-space ${ }^{6} \mathcal{M}:=<\left(r^{j}\right)_{j \in J}>$ generated by the $J$ columns of $V$ of the contingent claim space $\mathbb{R}^{S}$.

We assume that the economy has incomplete financial market. That is, the asset span is a proper sub-space of $\mathbb{R}^{S}$. This means that agents are constrained when making any transference of wealth from period-to-period and among states of nature. Let us denote by $\pi \in \mathbb{R}_{+}^{J}$ the price vector of the assets.

Lastly, the government exogenously determines the interest rate $r>0$ paid by the public debt which finances the tax cut. We assume that the government uses an auction to sell treasury bills and determine the riskless interest rate. ${ }^{7}$

An important remark is that the public debt, which is risk-free, is assumed not to be any asset spanning $\mathcal{M}$, but it might belong to it. ${ }^{8}$ This fact implies that, although agents who only have access to $\mathcal{M}$ to transfer wealth do not directly negotiate public debt, they will be able to build a portfolio to replicate the payoff of the public debt whenever such payoff belongs to $\mathcal{M}$. This issue will be better explained in the next section.

\subsection{Risk-free payoff and riskless asset}

A risk-free payoff is any vector $z$ belonging to $R^{S}$, such that $z_{s}$ is independent of the state of nature. In this case, this payoff will be denoted by $\lambda \mathbf{1} \in \mathbb{R}^{S}$, being $\lambda \in \mathbb{R}$ a state independent claim. An immediate consequence is that if the risk-free payoff is marketable, i.e. $\mathbf{1} \in \mathcal{M}$, then there exists a portfolio $\theta \in R^{J}$ such that $V \theta=1$.

Every asset is represented by its payoff. If this payoff is risk-free, the asset is said to be riskless. Riskless assets do not necessary exist unless the markets are complete. That is, $\mathcal{M}=R^{S}$.

\footnotetext{
${ }^{5}$ Notice that the symbol $S$ is used to represent both the set of states of nature as well as its cardinal.

${ }^{6}$ Mathematically, $\mathcal{M}:=\left\{V \theta: \theta \in \mathbb{R}^{J}\right\}$

${ }^{7}$ This interest rate, $r>0$, might be a function of the basic interest rate of the economy. However, it is not an instrument of the monetary policy, which is not under consideration in this paper. Also, we are not concerned with the holders of the public debt issued in the auction that determines $r$. $\mathcal{M}$

${ }^{8}$ Let $r^{1}=\left(1,0, \frac{1}{2}\right), r^{2}=\left(0,1, \frac{1}{2}\right)$ be two assets spanning $\mathcal{M}$. It is easy to verify that $(1,1,1) \in$
} 


\section{$2.2 \quad$ Fiscal policy}

The government enters in the economic scene to implement the following fiscal policy:

$$
\tilde{T}_{o}-T_{o}=-D, \text { and } \tilde{T}-T=(1+r) D=-(1+r)\left(\tilde{T}_{o}-T_{o}\right),
$$

where capital letters represent sum over $h=1,2, \ldots, H$ individuals. In the rest of the paper, lower-case letters will stand for individual-specific variables.

In the first period, the tax cut $\left(\tilde{T}_{o}-T_{o}\right)$ is financed by issuing debt, $D$. In the second period, taxes are increased by the amount of principal plus interest due on the debt issued in the previous period, $\tilde{T}-T=(1+r) D$. This fiscal policy can be thought of as a tax cut that leaves the present value of the government spending unchanged. ${ }^{9}$ In general, it is the effect of this kind of fiscal policy that the RET addresses.

Remark 1. The definition of tax cut does not imply that the risk-free payoff paying $(1+r)$ belongs to the asset span, since $r>0$ is taken as exogenous and, in principle, might or might not belong to $\mathcal{M}$.

\subsection{The taxpayer's problem}

Given the asset prices $\pi \in \mathbb{R}_{+}^{J}$ and tax obligations $\tau=\left(t_{o}, t \mathbf{1}\right) \in R_{++}^{1+S}$, which are assumed to be equal among individuals, each agent $h \in H$ chooses $(x, \theta)$ in order to maximize $U^{h}(x)$ subject to the following two-period budget constraints:

$$
x_{o}+\pi \theta=\omega_{o}^{h}-t_{o},
$$

and

$$
x_{s}=\omega_{s}^{h}+V_{s} \theta-t, s \in \Omega,
$$

where $V_{s}$ is the $s-t h$ row of the payoff matrix $V$.

The first constraint says that the value of the initial endowment, after taxes, finances the consumption, $x_{o}$, and investment, $\pi \theta$. The second budget constraint states that the net of taxes ex-post income (which includes endowment and financial income) finances consumption in each state of nature. Thus, taxpayer $h^{\prime} \mathrm{s}$ budget set is defined to be

$$
B^{h}(\pi, V, \tau)=\left\{x \in R_{+}^{1+S}: \exists \theta \in R^{J},(2) \text { and (3) are satisfied }\right\}
$$

If the tax-cut defined by (1) is enacted, then (2) and (3) will become:

$$
x_{o}-\omega_{o}^{h}+\tilde{t}_{o}=-\pi \theta-d,
$$

and

$$
\tilde{x}-\tilde{\omega}^{h}+\tilde{t}=V \theta+(1+r) d .
$$

\footnotetext{
${ }^{9}$ Note that $\tilde{T}-T$ is not state-dependent because of $D$.
} 
Remark 2. Equations (2') and (3') only capture the effects of the fiscal policy on the budget set. However, theoretically, they are the same as if the individuals were purchasing public debt at a unit price and receiving a payoff of $(1+r)$. In addition, in our model, we are assuming that the public debt is not available for the consumers to purchase. Only risky assets are available for them, which might be used to replicate the public debt payoff. In case the public debt is marketable in an incomplete market setting with heterogenous tax obligations, the fiscal policy will be neutral if there is no redistribution of the tax burden among the individual agents, as in Gale (1990).

The question, now, is whether agents can neutralize the government $\operatorname{debt}^{10}$ $(1+r) d$, as highlighted by Carmichael (1982), and not whether government bonds $d$ are considered as net wealth, as defined by Barro (1974). The validity of the RET rests on whether agents are able to neutralize the government debt, and not on the perception they have on that debt.

To be more precise, we will define the RET next. Firstly, we define the individual demand set $\psi^{h}(\pi, V, \tau)$ to be the set of all feasible-budget consumption plans such that there is no other feasible-budget consumption plan yielding a greater utility. Formally, this set is defined as:

$$
\psi^{h}(\pi, V, \tau)=\left\{x \in B^{h}(\pi, V, \tau): \neg\left[\exists x^{\prime} \in B^{h}(\pi, V, \tau): U^{h}\left(x^{\prime}\right)>U^{h}(x)\right]\right\} .
$$

Then, we have that:

Definition 1 The RET is said to hold if any fiscal policy defined by (1) does not affect individual demand sets, $\psi^{h}(\pi, V, \tau), \forall h \in H$, and therefore neither the aggregated demand set $\sum_{h \in H} \psi^{h}(\pi, V, \tau)$.

\section{The Role of the Law of One Price}

Our first result states that if the government implements a fiscal policy as described by (1), then agents will neutralize the government debt if, and only if, they are able to build a portfolio which replicates the risk-free payoff. To prove this result, we redefine the budget set of each taxpayer in a convenient way by using the payoff pricing functional $q: \mathcal{M} \rightarrow R$ defined by $q(z)=\pi \theta$, with $V \theta=z$. This functional will be well defined and linear if the law of one price is satisfied. ${ }^{11}$ Using this fact, the taxpayer's problem can be written as:

$$
\max _{\left(x_{o}, \tilde{x}\right) \in B^{h}(q, \mathcal{M}, t)} U^{h}\left(x_{o}, \tilde{x}\right)
$$

\footnotetext{
${ }^{10}$ Which appear in the individual budget set because of the tax-cut enacted by the government, and not because the individuals have traded the public debt, since it is not available for them.

${ }^{11}$ Following Werner and LeRoy (2001), the financial markets $(V, \pi)$ is said to satisfy the law one price if for any two portfolios such that their payoffs are equal, then their prices must be equal as well.
} 
where $B^{h}(q, \mathcal{M}, \tau)=\left\{x \in \mathbb{R}_{+}^{1+S} \mid \exists z \in \mathcal{M}: x_{o}-\omega_{o}^{h}+t_{o}=-q(z)\right.$, and $\tilde{x}-\tilde{\omega}^{h}+t \mathbf{1}=$ $z$ \} where $q: \mathcal{M} \rightarrow R$ is the payoff pricing functional defined above. This means that the taxpayer's choice will depend only on the transference space and payoff pricing functional. ${ }^{12}$

By adapting the insight due to Carmichael (1982), the neutrality result is observed whenever individuals recognize the intertemporal implications of the public debt and the possibility of undoing the effects of changes in the fiscal policy by making portfolio adjustments.

The following Lemma explains how to do this.

Lemma 1 Suppose that the fiscal policy defined by (1) is enacted and the law of one price holds; then $\mathbf{1} \in \mathcal{M}$ if, and only if, $\forall h \in H, B^{h}(q, \mathcal{M}, \tau)=B^{h}(q, \mathcal{M}, \tilde{\tau})$ where $\tau$ and $\tilde{\tau}$ satisfy (1).

Proof. First of all, if the fiscal policy defined by (1) is enacted implies that $t_{o}=$ $\tilde{t}_{o}+d$, and $t=\tilde{t}-(1+r) d$. Now, let $x \in B^{h}(q, \mathcal{M}, \tau)$. Then $\exists z \in R^{S}$ such that $x_{o}-\omega_{o}^{h}+t_{o}=-q(z)$, and $\tilde{x}-\tilde{\omega}^{h}+t \mathbf{1}=z$ are satisfied. By hypothesis we know that the risk-free payoff $\mathbf{1}$ belongs to $\mathcal{M}$. Then, $\forall \alpha, \alpha \mathbf{1}$ also belongs to $\mathcal{M}$, as $\mathcal{M}$ is a sub-space. Moreover, following Werner and LeRoy (2001), the returns of all risk-free payoffs are the same. In particular, $\frac{(1+r) d}{q((1+r) d \mathbf{1})}=\frac{1+r}{1}$, which implies that the price of the payoff $(1+r) d \mathbf{1}$ is $d$.

Substituting $t_{o}$ and $t$ in the budget constraints above, one has that $x_{o}-\omega_{o}^{h}+\tilde{t}_{o}=$ $-q(z)-d$, and $\tilde{x}-\tilde{\omega}^{h}+\tilde{t} \mathbf{1}=z+(1+r) d \mathbf{1}$. Therefore, $\exists z^{\prime}=z+(1+r) d \mathbf{1} \in \mathcal{M}$, since $\mathcal{M}$ is a subspace of $R^{S}$. By using the fact that $q((1+r) d \mathbf{1})=d$, it follows that $q\left(z^{\prime}\right)=q(z)+d$. Notice that $q($.$) is linear because the law of price holds. Thus,$ $x_{o}-\omega_{o}^{h}+\tilde{t}_{o}=-q\left(z^{\prime}\right)$, and $\tilde{x}-\tilde{\omega}^{h}+\tilde{t} \mathbf{1}=z^{\prime}$, which implies that $x \in B^{h}(q, \mathcal{M}, \tilde{\tau})$. The converse is also true. To show this, we just have to undo the effects of the tax cut. Thus, Lemma 1 follows.

Now, we are ready to state and prove our main result.

Theorem 1 Under hypotheses of Lemma 1 one has that the RET holds if, and only if, agents are able to build a portfolio which replicates the risk-free payoff.

Proof. The "only if" part of Theorem 1 is straightforwardly implied from Lemma 1. It remains to prove the "if" part. Suppose that the RET holds. Then, by definition, one has that $\psi^{h}(q, \mathcal{M}, \tau)=\psi^{h}(q, \mathcal{M}, \tilde{\tau})$. Let $x$ be an element belonging to $\psi^{h}(q, \mathcal{M}, \tau)=\psi^{h}(q, \mathcal{M}, \tilde{\tau}) \subset B^{h}(q, \mathcal{M}, \tau)$. Then, $\exists z, z^{\prime} \in M$ such that $z=$ $x-\omega^{h}+t \mathbf{1}$ and $z^{\prime}=x-\omega^{h}+\tilde{t} \mathbf{1}$. Hence, $z^{\prime}-z=(\tilde{t}-t) \mathbf{1} \in \mathcal{M}$, since $\mathcal{M}$ is a subspace. But this last fact implies that $\mathbf{1} \in \mathcal{M}$, as we wanted to prove.

\footnotetext{
${ }^{12}$ It might seem that the taxpayer's choices depend on very abstract elements. However, from Riez's representation theorem, $q$ can be represented by a vector belonging to $\mathcal{M}$. Hence, as usual, the taxpayer's choices will depend only on asset prices, the payoff matrix and taxes.
} 
Remark 3. Theorem 1 states that $\mathbf{1} \in \mathcal{M}$ is a necessary and sufficient condition for the RET to hold. Notice, however, that the law of one price is needed only in order to prove that the condition $\mathbf{1} \in \mathcal{M}$ is sufficient. For the necessity, as shown in the proof of Theorem 1, we do not need to assume it.

The previous results also hold in equilibrium. An equilibrium for this economy consists of a tax collection $\left(T_{o}, T\right)$, debt level $D$, a system of asset prices $\pi$, and an allocation $\left(x^{h}, \theta^{h}\right)_{h \in H}$, such that the choices $\left(x^{h}, \theta^{h}\right)$ of each agent $h$ are optimal, the tax collection $\left(T_{o}, T\right)$ satisfies (1) above, ${ }^{13}$ and the asset market clears at prices $\pi$. The following corollary is straightforward.

Corollary 1 If the economy is in equilibrium, then the RET holds if, and only if, agents are able to build a portfolio which replicates the risk-free payoff in the economy.

Proof. If the economy is in equilibrium, then the non-arbitrage condition is satisfied and so is the law one price. Thus, Corollary 1 follows from Theorem 1.

\section{On the Failure of the RET}

An essential element for the results of Section 3 to hold is that the law of one price ${ }^{14}$ is satisfied. Without this, all results from Section 3 do not hold, and therefore the RET breaks down, even when the risk-free payoff belongs to the asset span of the economy. From a theoretical point of view, a sufficient condition for the law of one price to hold is that the matrix of payoffs has full rank. ${ }^{15}$

Since matrices with full column rank form an open set within all matrices, we can assume full column rank without any loss of generality. In case we have a payoff matrix that does not have full column rank, any small perturbation of its columns would recover that property. Thus, it is not sufficient that agents recognize the possibility of undoing the effects of changes in the fiscal policy but rather that they can actually do it. Without the law of one price, this would not be possible.

The crucial argument used to neutralize the debt depends on the hypothesis of a fixed payoff matrix with full column rank. However, if we allow the payoff matrix ${ }^{16}$ to vary, then the risk-free payoff might no longer belong to the span of the payoff matrix. This leads to a failure of the RET and this failure will be robust, in the sense that there will be an open set of payoff matrices such that

\footnotetext{
${ }^{13}$ This means that if another tax system $\left(\tilde{T}_{o}, \tilde{T}\right)$ is implemented, the resulting deficit, $\tilde{T}_{o}-T_{o}$, will be financed by government bonds $D$ and paid back by the surplus $\tilde{T}-T$ in the second period

${ }^{14}$ The concept of the law of one price does not have any relationship with the definition used in international finance. It is a property of the financial market represented by the payoff matrix. Following Werner and LeRoy (2001), the financial market $(R, \pi)$ is said to satisfy the law of one price if, for any two portfolios such that their payoffs are equal, then their prices must be equal as well.

${ }^{15}$ Meaning that there is no redundant assets.

${ }^{16}$ Whose span contains the risk-free payoff.
} 
the RET fails. Next, we formalize these facts by assuming the validity of the law one price. Under this law, we have shown that for a given financial structure, $\mathcal{M}=<r^{j}: j \in J>\subset R^{S}$, the RET holds if, and only if, $\mathbf{1} \in \mathcal{M}$. Equivalently, the RET does not hold if, and only if, $1 \notin \mathcal{M}$.

A natural question that arises is what happens if the financial structure changes. This question is legitime since the financial market is represented by $J$ risky assets and, therefore, its span $\mathcal{M}$ might change. In order to address this question, we will reformulate the statement $1 \in \mathcal{M}$ in a more convenient way.

We start by defining the following set:

$$
\mathcal{F}=\left\{\left(r^{1}, \ldots, r^{J}\right) \in\left(R^{S}\right)^{J}: g\left(r^{1}, \ldots, r^{J}\right)=0\right\},
$$

where $g: R^{J S} \rightarrow R$ is given by

$$
g\left(r^{1}, \ldots, r^{J}\right)=\operatorname{dist}(\mathbf{1}, \mathcal{M}) \text { with } \mathcal{M}=<r^{j}: j \in J>.
$$

Hence, the condition that defines $\mathcal{F}$ is equivalent to state that $\mathbf{1} \in \mathcal{M}$. This leads to the following proposition whose proof is straightforward.

Lemma $2 R E T \Leftrightarrow g\left(r^{1}, \ldots, r^{J}\right)=0$.

The following corollary states the failure of the RET.

Corollary 1 There is an open $\mathcal{R} \subset R^{J S}$ such that, for all $\left(r^{1}, \ldots, r^{J}\right) \in \mathcal{F}$, the RET fails.

Proof Lemma 2 implies that the RET holds for all $\left(r^{1}, \ldots, r^{J}\right) \in \mathcal{F}$. Continuity of $g$ implies that $\mathcal{F}$ is closed and, therefore, its complement is open. Thus Lemma 2 follows if we define $\mathcal{R}$ to be $\mathcal{F}^{c}$.

Remark 4. Corollary 1 is about the size of the set where the exogenously given financial structure is allowed to vary. What about the size of the set of the endogenous variables? That is, what is the "size" of the set $\Theta:=\left\{\theta \in R^{J}: R \theta=1\right\}$ ? If the RET holds, then $\Theta$ is a single set, given that $V$ is being assumed to have full column rank and thus to be an injective transformation. Therefore, its Lebesgue measure is zero. This means that, if we consider a measure of probability which is absolutely continuous with respect to Lebesgue measure, the agent's probability of replicating the risk-free payoff is null.

\section{Concluding Remarks}

In this paper, we showed that in general the RET does not hold in economies with incomplete financial markets. However, if we allow the risk-free payoff belongs to the span of the payoff matrix, then RET is restored. The converse was also proved to be true. This result, however, strongly depends on the law of one 
price. ${ }^{17}$ Under this law, agents are able to undo the effects of any change in the fiscal policy whenever the risk-free payoff belongs to the span of the payoff matrix which is assumed to be fixed.

The RET, however, does not hold if we allow the payoff matrix to vary, meaning that the payoffs of available assets could change, say, by external shocks. More precisely, if the the risk-free payoff belongs to the span of the payoff matrix, then it will no longer belong to that span if there is a slight perturbation to its columns. Finally, we showed that the failure of RET is robust, in the sense that there exists an open set of payoff matrices such that the RET fails.

\section{References}

Auerbach, A. J. \& Kotlikoff, L. J. (1987). Dynamic Fiscal Policy. Cambridge University Press, Cambridge.

Barro, R. J. (1974). Are government bonds net wealth? Journal of Political Economy, 82:1095-117.

Barro, R. J. (1976). Perceived wealth in bonds and social security and the Ricardian equivalence theorem: Reply to Feldstein and Buchanan. Journal of Political Economy, 84:343-350.

Barro, R. J. (1989). The Ricardian approach to budget deficits. Journal of Economic Perspectives, 3:37-54.

Bassetto, M. \& Kocherlakota, N. (2004). On the irrelevance of government debt when taxes are distortionary. Journal of Monetary Economics, 51:299-304.

Bernheim, B. D. (1987). Ricardian equivalence: An evaluation of theory and evidence. In Fischer, S., editor, NBER Macroeconomics Annual, volume 2. MIT Press, Cambridge.

Biondo, A. E. (2010). The law of one price: Survey of a failure. Theoretical and Practical Research in Economic Fields, I:168-182.

Braun, R. A. (1994). How large is the optimal inflation tax? Journal of Monetary Economics, 34:201-214.

Buchanan, J. M. (1976). Barro on the Ricardian equivalence theorem. Journal of Political Economy, 84:337-342.

Carmichael, J. (1982). On Barro's theorem of debt neutrality: The irrelevance of net wealth. American Economic Review, 72:202-213.

\footnotetext{
${ }^{17}$ A stronger assumption than the law of one price is the non-arbitrage condition, which was not assumed because it would reduce the set of all payoff matrices.
} 
Chan, L. K. (1983). Uncertainty and the neutrality of government financing uncertainty policy. Journal of Monetary Economics, 11:351-372.

Dubey, P., Geanakoplos, J., \& Shubik, M. (2005). Default and punishment in general equilibrium. Econometrica, 73:1-37.

Elmendorf, D. W. \& Mankiw, N. G. (1999). Government debt. In Taylor, J. B. \& Woodford, M., editors, Handbook of Macroeconomics. North Holland, Amsterdam.

Evans, G. W., Honkapohja, S., \& Mitra, K. (2012). Does Ricardian equivalence hold when expectations are not rational? Journal of Money, Credit and Banking, 44:1259-1283.

Feldstein, M. (1974). Social security, induced retirement, and aggregate capital accumulation. Journal of Political Economy, 82:905-26.

Gale, D. (1990). The efficient design of public debt. In Draghi, M. \& Dornbusch, R., editors, Public Debt Management: Theory and History. Cambridge University Press, Cambridge.

Geanakoplos, J. (1990). An introduction to general equilibrium with incomplete asset markets. Journal of Mathematical Economics, 19:1-38.

Hayashi, F. (1987). Tests for liquidity constraints : A critical survey and some new observations. In Truman, F. \& Bewley, A., editors, Advances in Econometrics, volume 2, pages 91-120. Cambridge University Press, Cambridge.

Hayford, M. (1989). Liquidity constraints and the Ricardian equivalence theorem: Note. Journal of Money, Credit and Banking, 21:380-387.

Holmstrom, B. \& Tirole, J. (1998). Private and public supply of liquidity. Journal of Political Economy, 106:1-40.

Lamont, O. A. \& thaler, R. H. (2003). Anomalies: The law of one price in financial markets. Journal of Economic Perspectives, 17:191-202.

Magill, M. \& Quinzii, M. (2002). The Theory of Incomplete Markets. The MIT Press, Cambridge.

McGrattan, E. R. (1994). The macroeconomic effects of distortionary taxation. Journal of Monetary Economics, 33:573-601.

Panadés, J. (2001). Tax evasion and Ricardian equivalence. European Journal of Political Economy, 17:799-815.

Ricciuti, R. (2003). Assessing Ricardian equivalence. Journal of Economic Surveys, $17: 55-78$ 
Seater, J. (1993). Ricardian equivalence. Journal of Economic Literature, 31:142190.

Trostel, P. A. (1993). The effect of taxation on human capital. Journal of Political Economy, 101:327-50.

Wallace, N. (1981). A Modigliani-Miller theorem for open-market operations. American Economic Review, 71:267-274.

Werner, J. \& LeRoy, S. F. (2001). Principles of Financial Economics. Cambridge University Press, Cambridge.

Yotsuzuka, T. (1987). Ricardian equivalence in the presence of capital market imperfections. Journal of Monetary Economics, 20:411-436. 